\title{
PATOLOGIAS EM HABITAÇÃO DE INTERESSE SOCIAL: UMA REVISÃO
}

\begin{abstract}
Ailton Pires Leal ${ }^{1}$
RESUMO: A proposta deste trabalho é compreender as manifestações patológicas em Habitações de Interesse Social (HIS), destacando suas relações com as etapas de construção deste tipo e possíveis soluções para os problemas patológicos. Este propósito maior foi alcançado por meio de uma pesquisa bibliográfica, qualitativa. Com base na literatura, apurou-se que as fissuras representam as patologias mais comuns nesse tipo de habitação, seguidas de deslocamento de revestimento, umidade e bolor. De forma geral, os problemas patológicos têm relação com as fases de projeto e de execução, evidenciando que maior rigor é necessário. Ainda, observou-se que as possíveis soluções para as manifestações patológicas levantadas dependem de projetos de construção com nível de qualidade desejável. Torna-se fundamental profissionais adequadamente qualificados, especialmente, na fase de execução, visto que algumas patologias decorrem de ações mal executadas. Ademais, considera-se que os objetivos colocados às HIS atendem às necessidades dos usuários.
\end{abstract}

Palavras-chave: Danos. Habitações de interesse social. Manifestações patológicas.

ABSTRACT: The purpose of this work is to understand the pathological manifestations in Social Interest Housing ( $\mathrm{SIH}$ ), highlighting their relationship with the stages of construction of this type and possible solutions to pathological problems. This greater purpose was achieved through a qualitative bibliographic search. Based on the literature, it was found that cracks represent the most common pathologies in this type of housing, followed by displacement of coating, moisture and mold. In general, pathological problems are related to the design and execution phases, showing that greater rigor is necessary. Still, it was observed that the possible solutions for the raised pathological manifestations depend on construction projects with a desirable level of quality. Properly qualified professionals are essential, especially in the execution phase, since some pathologies result from poorly performed actions. In addition, it is considered that the objectives placed on HIS meet the needs of users.

Keywords: Damage. Social interest housing. Pathological manifestations.

\section{INTRODUÇÃO}

\footnotetext{
I Discente do curso de Engenharia Civil do UNIAGES- Centro Universitário-Paripiranga, BA. E-mail: ailtonpiresleal@hotmail.com.
} 
O movimento de melhorias em torno da construção civil foi impulsionado pelo crescimento demográfico, urbano e econômico, à medida que foram estabelecendo novas tecnologias. Em linhas gerais, verifica-se que esse é um setor que ocupa uma importante posição na economia dos países, incluindo o Brasil. Isso porque representa uma relevante fatia dentre os setores que integram o Produto Interno Bruto (PIB) do país, gerando, com efeito, novos conhecimentos que foram sendo desenvolvidos no âmbito da engenharia civil.

Apesar de todos os benefícios que circundam a área da engenharia civil, incluindo o aprimoramento de práticas orientadas a novos conhecimentos desse setor, alguns aspectos merecem atenção, a exemplo das manifestações patológicas nas edificações. Isso, pois, representa um fator de desvalorização dos imóveis, implicando em má qualidade do produto ofertado.

De maneira mais restrita, este estudo se concentrou na investigação das manifestações patológicas em Habitações de Interesse Social (HIS), construídas com especial finalidade de atenuar o déficit habitacional. Tal medida é importante, haja vista que a especulação imobiliária, sobretudo, nas grandes cidades, tende a dificultar o acesso da população de baixa renda à aquisição de um imóvel.

Tem-se que as HIS constituem exemplos de construções que são executadas de forma relativamente rápida. Desta forma, podem acontecer patologias que tendem a conduzir essas edificações à deterioração precoce. Em síntese, patologias na construção civil são entendidas como construções que apresentam defeitos, podendo comprometer suas funções básicas, necessitando de diagnóstico e tratamento.

No contexto brasileiro, as HIS tiveram destaque ao longo dos anos, quando os governos aplicaram grandes volumes de recursos financeiros na construção civil. A intenção é dispor à população de baixa renda a possibilidade de adquirir sua casa própria. Ainda que as políticas públicas com essa finalidade tenham demonstrado êxito referente ao déficit habitacional, verificam-se diversas manifestações patológicas nesses locais, fazendo-se necessário estudar as causas desses problemas, a fim de proporcionar a retroalimentação e a elaboração dos projetos deste tipo de construção. 
Com base nesse contexto, este estudo teve como objetivo compreender as manifestações patológicas em HIS, destacando suas relações com as etapas de construção deste tipo e possíveis soluções para os problemas patológicos.

As justificativas para a realização desta investigação consideraram que é essencial atualizar e integrar o conhecimento produzido na literatura científica, uma vez que novos métodos e tecnologias são incorporados na construção deste tipo de habitação. Adicionalmente, em levantamentos preliminares, foi verificado que as HIS apresentam, relativamente, patologias evitáveis nas fases de projeto e de execução da obra. Assim, a pesquisa em lide atualiza as informações, fornecendo maiores esclarecimentos quanto a necessidade de elevar a qualidade de obras desse tipo.

Em relação à metodologia, considerando os objetivos delimitados, optou-se pela pesquisa bibliográfica, visando construir a revisão de literatura, de abordagem qualitativa. Assim, recorreu-se a publicações de relevância científica, como livros, artigos e outras produções, desde que estivessem de acordo com a proposta deste trabalho.

\section{POLÍTICAS HABITACIONAIS NO BRASIL}

Em linhas gerais, o problema habitacional figura como algo antigo no contexto histórico das cidades. Todavia, a partir da Revolução Industrial, aliada a um processo acelerado de urbanização, essa problemática se potencializou e trouxe reflexos à contemporaneidade. Tem-se que o aumento relevante da demanda por moradias em todas as cidades do Brasil se apresenta como um dos principais problemas a serem enfrentados pelo poder público do país (MONTEIRO; VERAS, 2017).

O olhar sobre a linha do tempo concernente à trajetória da habitação social no Brasil mostra que, no decorrer dos anos, o poder público, em diferentes momentos, buscou atenuar essa questão, balizando-se em alternativas diferentes, com inclinação para o uso de recursos financeiros e econômicos. Dentre as primeiras tentativas de dispor moradias, os responsáveis pela provisão habitacional eram representados por Institutos e Caixas de Aposentadorias e Pensões, que, por meio das carteiras prediais, faziam uma atuação de forma fragmentada. Isso, pois, o atendimento era reservado somente aos associados (BRUNA, 2015). 
O primeiro marco institucional consiste na criação da Fundação da Casa Popular, a qual foi instituída pelo Decreto-Lei n⿳o. 9.218, de primeiro de maior de 1946. Trata-se do primeiro órgão, em nível nacional, com a finalidade de proporcionar aos cidadãos brasileiros ou estrangeiros com mais de dez anos no país ou com filhos brasileiros, a construção ou aquisição de moradia própria, podendo ser em zona urbana ou rural (CUNHA; SILVA, 2018).

Mesmo considerando que a aquisição de moradia priorizava a população economicamente desfavorecida, a referida Fundação obteve representatividade baixa, haja vista que sua produção média anual se limitava a 900 moradias. Além disso, a dependência de recursos orçamentários e sua estrutura institucional constituíram-se como entraves no alcance de suas metas, incluindo a contenção da crise de moradia em função da urbanização acelerada (AZEVEDO; ANDRADE, 20II).

No ano de 1964, o governo brasileiro criou o Banco Nacional da Habitação (BNH) e o Serviço Federal de Habitação e Urbanismo (SFHU). Destaca-se que as fontes de recursos financeiros do BNH vieram, sobretudo, por meio do Fundo de Garantia por Tempo de Serviço (FGTS) e do Sistema Brasileiro de Poupança e Empréstimo (SBPE) (AZEVEDO; ANDRADE, 20II).

O referido serviço se destinava à construção de unidades prontas. Entretanto, até mesmo pelo contexto do regime militar em que estava inserido, era rígido e centralizado, além de não incorporar as práticas realizadas pela população que dispunha de poucos recursos para construir a própria moradia. Destaca-se que o $\mathrm{BNH}$ foi impedido de conceder benefícios, impactando especialmente no acesso ao financiamento das camadas de baixa renda. Quando contemplada, a população adquiria imóveis de baixa qualidade arquitetônica e urbanística, além de isolados da malha urbana (PERINI, 2017).

Até o ano de 1986, o BNH financiou mais de 4 milhões de moradias, bem como expandiu as redes de água e esgoto em diversas cidades do Brasil, a partir do Plano Nacional de Saneamento. Mesmo considerando esses números, apreende-se que esse sistema não mostrou grande eficácia no atendimento da população crescente, uma vez que focou na população de média renda. Em 1986, o BNH foi extinto em meio a um cenário de 
crise, provocada pela ineficiência do financiamento, aliado às altas taxas de inflação e à crescente inadimplência dos adquirentes (PERINI, 20I7).

A partir de então, até o ano de 1994, diferentes órgãos sucederam na gestão da política habitacional do governo federal. Isso deixou clara uma instabilidade política e institucional, especialmente, pela falta de continuidade de projetos e ausência de estratégias. Essa desestruturação da perda da capacidade decisória do Estados, juntamente com a queda dos recursos para o setor, colocou a atribuição financeira para a Caixa Econômica Federal, vinculada ao Ministério da Fazenda, quando, anteriormente, a habitação encontrava-se vinculada ao Ministério do Desenvolvimento Urbano e Meio Ambiente (SANTOS; DUARTE, 2010).

Importa salientar que a Constituição Federal do Brasil de 1988 transferiu atribuições sobre esse tema para os Estados e Municípios, fator que colocou a habitação como uma competência conjunta das três esferas de governo. Esse processo de descentralização na forma de habitação social nas esperas municipal e estadual se configurou como momento de crescimento de experiências, caracterizada pela heterogeneidade de iniciativas. Não obstante, revelaram pouca articulação, diante da inexistência de uma política nacional, mesmo com algum sucesso na esfera municipal que, no entanto, carecia de recursos (BRASIL, 2004).

Ainda que diferentes iniciativas tenham se estruturado ao longo do tempo, somente no ano de 2005, na gestão do presidente Lula, percebeu-se maior aproximação entre o capital financeiro e o setor imobiliário. Com efeito, houve uma ampliação da estrutura de capital direcionada à incorporação de novos terrenos, incluindo o aumento da base de capital, bem como da capacidade de endividamento e do capital de giro que sustentam a continuidade das obras (RUFINO, 2016).

Acrescenta-se que o Ministério das Cidades, criado em 2003, se configura como um relevante marco institucional para o Brasil, sobretudo, porque constituiu-se enquanto órgão nacional mais importante no enfrentamento do problema da moradia e desenvolvimento urbano. Sublinha-se que este Ministério possui estrutura de coordenação, gestão e 
formulação da Política Nacional de Desenvolvimento Urbano. Ainda, engloba, de forma integrada, as políticas relativas à cidade, buscando sanar o problema institucional ocasionado desde a extinção do BNH (BONDUKI, 2008).

Um importante marco legal relacionado à habitação no Brasil se deu com Política Nacional de Habitação, em 2004. A política citada visa tornar universal o acesso à moradia digna, assim como busca promover a urbanização, regularização e inserção dos assentamentos precários às cidades. Suas finalidades são diversas, e ainda incluem o fortalecimento do papel do estado na gestão da Política e na regularização dos agentes privados, além de tornar a questão habitacional uma prioridade nacional, neste caso, por meio da integração, articulação e mobilização dos diferentes níveis de governo, dentre outros objetivos (BRASIL, 2004).

A PNH prevê diferentes instrumentos para alcançar seus objetivos, quais sejam: um Sistema Nacional de Habitação $(\mathrm{SNH})$ e dois subsistemas - Sistema Nacional de Habitação de Interesse Social (SNHIS) e o Sistema Nacional de Habitação de Mercado (SNHM); e a elaboração do Plano Nacional de Habitação, o qual deve estabelecer alvos a médio e longo prazos, além de linhas de financiamento e os programas de provisão, urbanização e modernização da produção habitacional (BRASIL, 2004).

$\mathrm{O}$ ano de 2008 ficou marcado por uma crise econômica internacional no setor imobiliário, tendo como gênese os Estados Unidos da América, tendo repercussões, inclusive, no Brasil. Como resultado, as ações que as construtoras tinham na Bolsa de Valores foram desvalorizadas, implicando diretamente na queda de investimentos das empresas, entrando em endividamento e acúmulo de estoques (CARVALHO; MEDEIROS, 2017).

A reação do poder público frente ao quadro de crise apresentado consistiu em investir no âmbito habitacional, a fim de estimular criação de emprego e gerar renda. Esse movimento estimulou outro marco legal, representado pelo Programa Habitacional Minha Casa, Minha Vida (PMCMV), em 2009, em parceria entre a Casa Civil e o Ministério da Fazenda, integrando o Programa de Aceleração do Crescimento (PAC). Em função disso, a questão habitacional foi desvinculada da $\mathrm{PNH}$. 
Em síntese, o PMCMV foi instituído a partir da Lei noo. II.977/o9, tendo como objetivo nuclear criar mecanismos de incentivo à produção e aquisição de novas unidades habitacionais ou requalificação de imóveis em áreas urbanas e produção ou reforma de habitações em áreas rurais (BRASIL, 2009).

\section{ORIGEM DOS DEFEITOS ESTRUTURAIS DA CONSTRUÇÃO}

O defeito estrutural significa qualquer defeito em um elemento estrutural de uma construção, que é atribuível a projeto defeituoso, mão de obra defeituosa ou defeituosa ou material defeituoso e, às vezes, qualquer combinação destes. Os motivos que ocasionam o desempenho insatisfatório de algumas estruturas são diversos, a exemplo de falhas involuntárias, imperícia, deterioração e acidentes, dentre outros fatores, que se aliam às limitações na área do conhecimento (MAZER, 2008).

No que se refere à qualidade do empreendimento, tem-se que a etapa de concepção deve acontecer de modo a garantir total satisfação do cliente, assim como a facilidade de execução e, também, a possibilidade de realização da adequada manutenção. Em relação à etapa de execução, o intuito é buscar a fidedignidade de atendimento ao projeto, visando a possibilidade de extensão da vida útil da obra (CAMPOS, 20II).

De maneira geral, entende-se que as intervenções são mais eficazes e eficientes, além de possuírem um custo menor, aliadas à maior facilidade de implantação. Essa máxima é asseverada pela Lei de Sitter que, balizada em uma progressão geométrica, divide as etapas de construção e de uso em quatro períodos distintos, quais sejam: projeto; execução; manutenção preventiva; e manutenção corretiva, esta depois de identificada determinada patologia (PEREIRA, 20II). A representação imagética da referida Lei pode ser visualizada na Figura I

Figura I - Lei de Sitter.

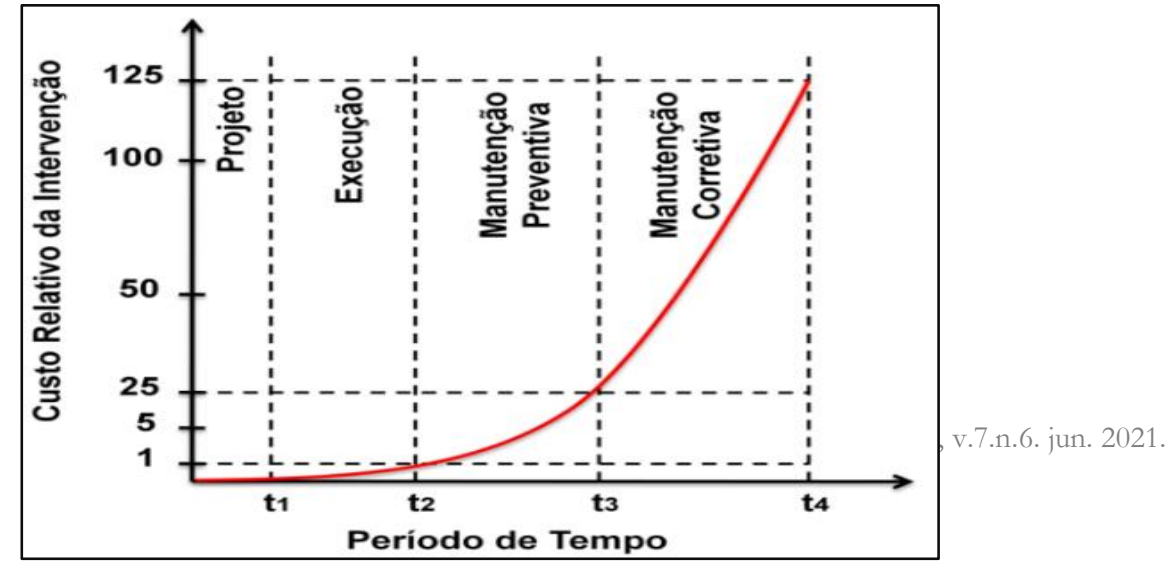


Fonte: Pereira (2011).

Com base na Figura i e nos pressupostos da Lei de Sitter, os custos aplicados em intervenções tardias em estruturas ascendem em progressão geométrica em razão de cinco, quando conflitados com os custos referentes às medidas preventivas estabelecidas na etapa de projetos. Esses postulados, então, sugerem que é necessário traçar um cronograma físico-financeiro do empreendimento, de modo a prevenir a manifestação de defeitos estruturais, haja vista que eleva progressivamente os custos, quando podem ser evitados.

De certa maneira, os problemas patológicos são implicados por falhas que acontecem durante a realização de uma ou mais atividades referentes ao processo de construção civil. Não obstante, há casos em que tais consequências decorrem de catástrofes naturais, em que a violência com que acontecem e sua imprevisibilidade representam fatores predominantes para a presença dos defeitos estruturais. Em todo caso, o processo de construção deve estar ancorado na concepção do projeto, em sua execução e utilização (JONOV et al., 2013).

As etapas de projeto, execução e utilização são fundamentais para o resultado do empreendimento, em que se torna fundamental que cada uma delas aconteça com o mínimo de erros possível, para que a vida útil planejada seja alcançada. Quando essas fases são executadas com um bom nível de qualidade, a tendência é que aconteça um menor número de manifestações patológicas, elevando a satisfação do cliente. Nesse sentido, é relevante que o responsável por cada uma das etapas esteja ciente das falhas que podem ocorrer, de modo a evitá-las. O Quadro I, a seguir, mostra um modelo de identificação de problemas estruturais, considerando a origem e o responsável por cada etapa.

Quadro I - Identificação da origem do problema.

\begin{tabular}{|c|c|}
\hline Origem da falha & Responsável pela falha \\
\hline Fase de projeto & Projetista \\
\hline
\end{tabular}




\begin{tabular}{|c|c|}
\hline Qualidade do material & Fabricante \\
\hline Etapa de execução & $\begin{array}{c}\text { Mão de obra ou fiscalização e/ou construtora } \\
\text { omissos }\end{array}$ \\
\hline Etapa de uso & Operação e manutenção \\
\hline Outros & ...... \\
\hline
\end{tabular}

Fonte: Silva e Janov (2019).

As etapas de uma obra podem estar sob diferentes lideranças e, conforme o Quadro I, em cada uma delas há um responsável pelas falhas, desde o projetista, na fase de projeto, até a equipe de operação e manutenção, na fase de uso do empreendimento. Sendo assim, é fundamental que esses responsáveis compreendam suas funções e estejam atentos aos possíveis problemas patológicos que podem surgir, na tentativa de evitá-los ou causar o menor dano.

Diante da estrutura considerada doente, torna-se necessário compreender o que a levou ao desenvolvimento da doença, a fim de deixar claro suas causas, antes da prescrição e do consequente reparo. Por este motivo, é basilar conhecer as origens da deterioração, haja vista que seus benefícios podem transpor o reparo demandado, pois, podem garantir que a estrutura não volte a se deteriorar, considerando uma possível previsibilidade (MAZER, 2008). Dada a importância da compreensão de cada uma das etapas de construção descritas neste item, na sequência, serão abordados alguns aspectos sobre as patologias geradas em cada uma delas.

\section{METODOLOGIA}

Para que objetivos estabelecidos neste estudo fossem alcançados em sua integralidade, delineou-se a metodologia apoiada em uma pesquisa com abordagem qualitativa que, de acordo conforme Gil (2010), representa uma possibilidade de o pesquisador realizar inferências acerca da realidade investigada. Dessa forma, o investigador visa a interpretação de tal realidade, o que, por sua vez, demanda um delineamento sistematizado e consistente. Neste caso, a interpretação se inclinou em trabalhos que versaram sobre a recuperação estrutural em habitação social. 
No que se refere à natureza, a pesquisa é básica, uma vez que visou a discussão conhecimentos, sem a necessidade de alguma aplicabilidade em um futuro próximo. Considerando o delineamento proposto, este estudo ainda é classificado como exploratório. Isso porque buscou proporcionar maior familiaridade com a temática analisada (GIL, 2010), visando desvelar os conhecimentos produzidos acerca das possibilidades de recuperação estrutural em construção civil com o foco aqui estabelecido.

Em função de aspectos como os descritos, considerando que a coleta de dados seguiu conforme os objetivos delimitados, procedeu-se com a pesquisa bibliográfica. De maneira geral, compreende-se que esse tipo de pesquisa acontece quando o pesquisador se debruça sobre fontes secundárias de dados, que são constituídas por livros, artigos, teses, dissertações, anais de eventos e outros documentos de relevância científica, com a finalidade de constituir um levantamento bibliográfico.

\section{DISCUSSÃO}

Esta parte do estudo se reserva para apresentar e discutir os principais problemas patológicos em Habitações de Interesse Social (HIS). Como como se sabe, diferentes patologias na fase de uso são decorrentes da etapa de execução, por motivos diversos. Importa salientar, conforme a literatura, que diferentes patologias decorrentes $\mathrm{da}$ construção são evitáveis, sendo que envolvem principalmente a equipe de pessoal, desde a mão de obra pouco qualificada até a equipe de liderança. Na sequência, serão apresentados alguns trabalhos que focaram nos problemas patológicos.

Stuckert e Sobrinho Júnior (2016) realizaram um estudo com o objetivo de descrever as manifestações de patologias mais recorrentes em HIS, além de apresentar possíveis medidas de prevenção e/ou reparação dos danos, visando melhor desempenho e qualidade na vida útil das edificações. Para tanto, realizaram uma pesquisa de campo exploratória, em habitações de interesse social aleatórias no estado da Paraíba, pertencentes ao Programa Minha Casa, Minha Vida. A coleta de dados considerou um total de 12 residências, escolhidas aleatoriamente, com convite prévio aos participantes. Em campo, as manifestações patológicas encontradas foram fotografadas. 
No Gráfico I, verifica-se que a umidade aparece como o tipo de patologia mais frequente nas residências estudadas. Os autores identificaram a umidade são ocasionadas, sobretudo, pelas infiltrações nas esquadrias, decorrente de má instalação ou por vedação deficiente, tal como ocorre nas infiltrações na fachada. Já as umidades ascendente e descendente foram verificadas como sendo ocasionadas pela falta de impermeabilização dos alicerces, lajes e caixas d'águas. Nestes casos, havia presença de manchas, bolores e gotejamentos. Em relação às fissuras, foram identificadas principalmente nos cantos das esquadrias, sendo causadas pela falta ou deficiência de vergas e contravergas, que são responsáveis por absorver a concentração de tensões nas aberturas (STUCKERT; SOBRINHO JÚNIOR, 20I6). A Gráfico 2 evidencia os tipos de manifestações patológicas mais comuns.

Gráfico I - Manifestações patológicas mais comuns, na amostra

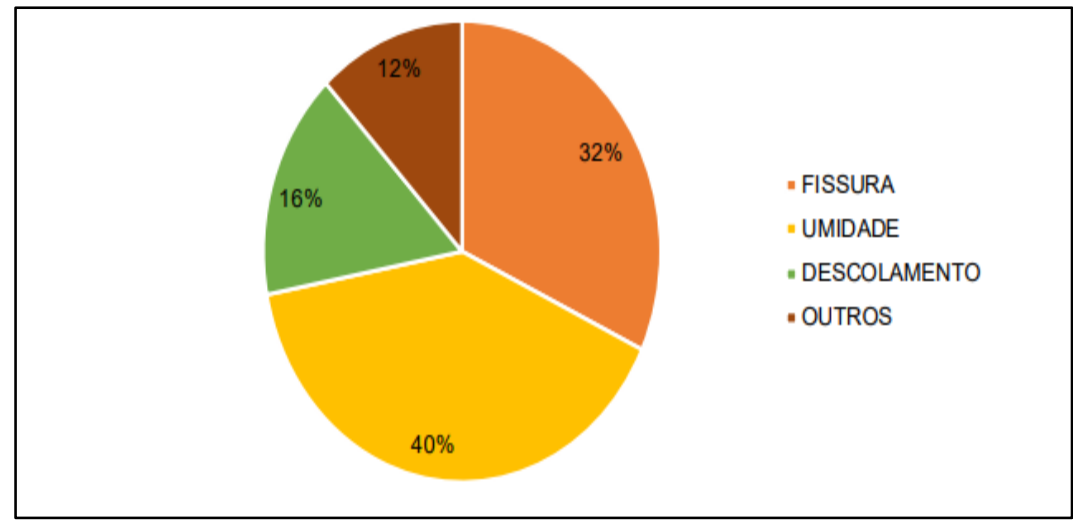

Fonte: Stuckert e Sobrinho Júnior (2016).

De maneira geral, ainda que o objetivo de reduzir o déficit habitacional seja alcançado pelo programa, alguns aspectos relativos à construção dessas edificações merecem atenção. Isso porque as patologias identificadas são reflexos de ineficiência nas etapas de planejamento e manutenção, mas, especialmente, na fase de exceção, haja vista que, nas estruturas, não continham materiais essenciais para seu bom desempenho.

Esse fato está em consonância com a literatura, quando, na revisão bibliográfica, foi indicado que uma parcela considerável de patologias acontece em decorrência da execução da obra. Isso requer maior atenção a todo ciclo produtivo, uma vez que a população usuária tem de permanecer em um local seguro para suas necessidades de moradia. Como se trata 
de habitações já entregues, é fundamental estabelecer a sensibilização dos profissionais quanto à elaboração de um projeto de qualidade, bem como sua execução qualificada e manutenção preventiva, a fim de evitar maiores custos, quando podem ser evitados, além de diminuir os riscos aos moradores.

Com um objetivo semelhante ao estudo de Stuckert e Sobrinho Júnior (2016), a pesquisa de Toralles e Souza (2015) buscou levantar as manifestações patológicas que ocorreram em unidades de HIS, neste caso, realizadas em diferentes tipos construtivos (alvenaria, concreto e fibrocimento), da cidade de Londrina, no Paraná, considerando suas áreas externas. Na pesquisa de campo, alguns critérios de inclusão das residências foram estabelecidos, tais quais: habitação sem modificações em relação ao projeto; habitações intermediárias (que não eram de esquina); residências com orientação das inclinações da cobertura voltadas para Leste/Oeste; e acesso viável à residência. Os dados foram coletados por meio de fichas de acompanhamento e fotografias.

$\mathrm{Na}$ identificação dos tipos de patologias classificadas como fissura, Toralles e Souza (2015) apuraram que, independentemente da orientação das fachadas, todas as paredes com aberturas apresentaram fissuras, em todas as tipologias construtivas analisadas, como pode ser visto no quadro 2.

Quadro 2- Fissuras nos vértices das aberturas das habitações de concreto, alvenaria e fibrocimento

\begin{tabular}{|c|c|c|c|c|c|}
\hline \multirow{2}{*}{ Tipologia } & \multirow{2}{*}{ Fachada } & \multicolumn{4}{|c|}{ Paredes } \\
\cline { 3 - 5 } & & Norte & Sul & Leste & Oeste \\
\hline \multirow{2}{*}{ Alvenaria } & Norte & I0o\% & Sem janela & I00\% & I00\% \\
\cline { 2 - 5 } & Sul & Sem janela & I00\% & I00\% & I00\% \\
\hline \multirow{2}{*}{ Concreto } & Norte & I00\% & Sem janela & I00\% & I00\% \\
\cline { 2 - 6 } & Sul & Sem janela & I00\% & 100\% & I00\% \\
\hline Fibrocimento & Sul & $66,7 \%$ & $33,3 \%$ & $66,7 \%$ & I00\% \\
\hline
\end{tabular}

Fonte: Toralles e Souza (2015).

Portanto, observa-se que as paredes Norte, Sul e Leste das habitações de fibrocimento foram as únicas que não alcançaram a ocorrência de $100 \%$ de fissuras. Sobre isso, a explicação possível, segundo Toralles e Souza (2015), é de que as influências do vão 
e das condições do clima local contribuíram para que este tipo de patologia fosse diminuído nessas construções.

Algumas causas das fissuras foram encontradas. Nas residências de paredes de fibrocimento, por exemplo, as mais comuns foram em função de movimentações diferenciadas (telha/telha e telha/pilar), e se relaciona à variação hidrotérmica. Nas habitações feitas com paredes de concreto, houve maior incidência de fissuras por deficiência de estanqueidade (figura I), relacionado à fuga da nata de cimento em função de falhas na confecção das fôrmas (TORALLES; SOUZA, 2015)

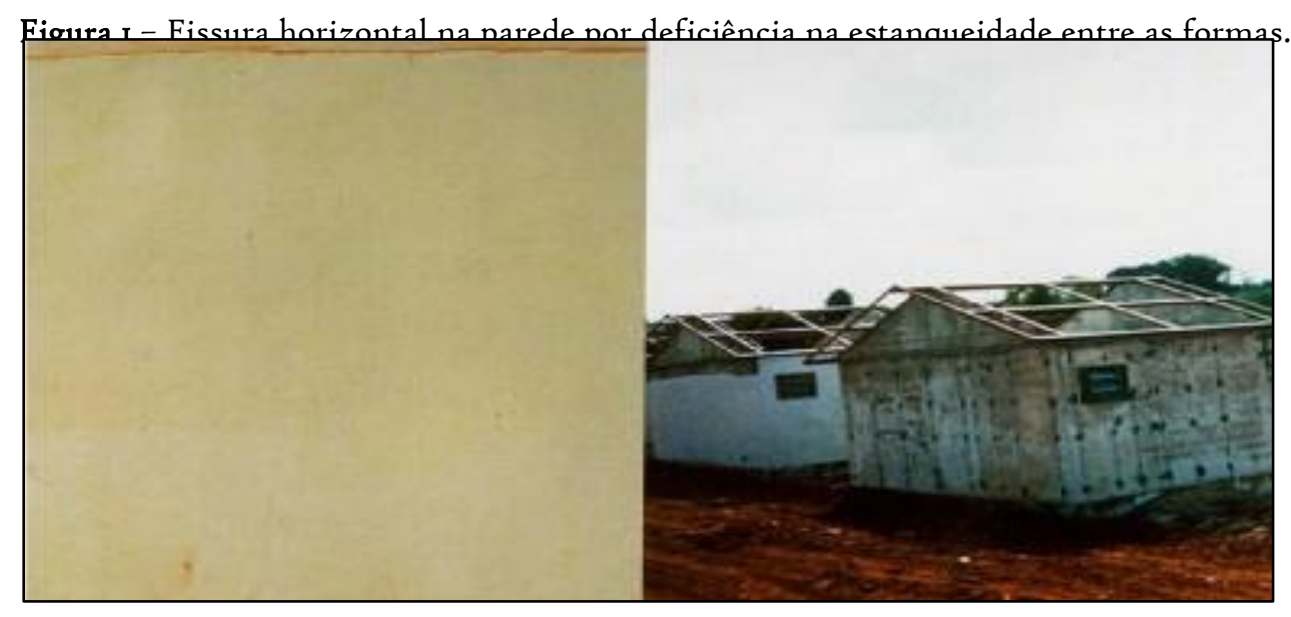

Fonte: Toralles e Souza (2015).

Como pode ser visualizado na figura I, a fissura horizontal percorre toda a altura da parede de concreto. Com a imagem da casa ainda em fase de construção, ao conflitar com a análise da residência pronta, concluiu-se que as fissuras são exatamente em que foram feitas as ligações dos painéis (TORALLES; SOUZA, 2015). Isso evidencia que é uma patologia relacionada à execução da obra.

Analisando patologias comuns às habitações de concreto e alvenaria de bloco cerâmico, algumas foram mais prevalentes, como o recalque, exposto na figura 2, a seguir.

Figura 7 - Fissura inclinada em função do recalque de fundação

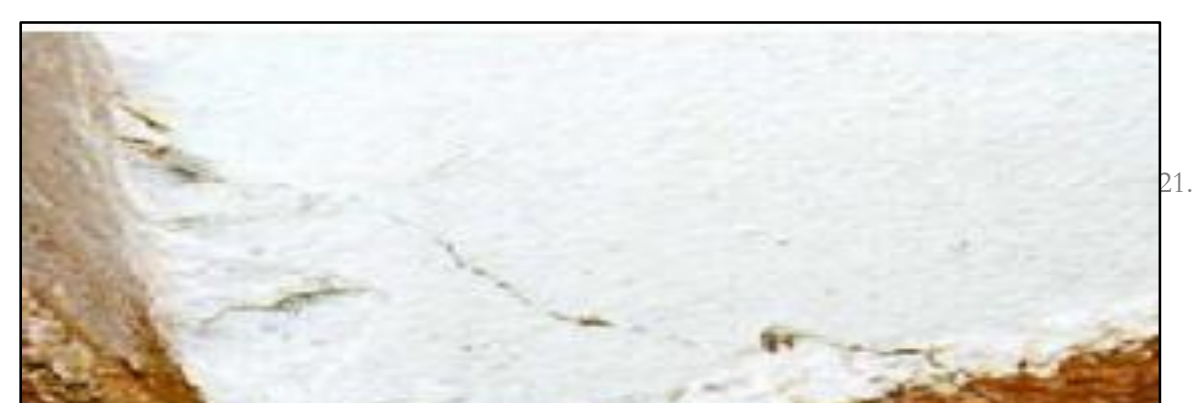


A explicação para o tipo de patologia apresentado na Figura 2 é de que resulta das cargas externas no solo, independentemente de suas proporções. Levando-se em conta que as deformações diferem ao longo do plano de fundações de uma obra, acaba implicando em tensões de grandes intensidades na estrutura, fazendo aparecer as fissuras, tendo a má execução da broca como uma das principais causas.

Outra patologia comum entre as tipologias analisadas foi a presença de bolor. Nas paredes das HIS estudadas, o bolor foi causado por ascensão de água por capilaridade, neste caso, a existência de fossa, bem como umidade por infiltração nas fachadas, além de umidade por condensação de vapores em locais fechados, a exemplo de banheiro e cozinha. O bolor consiste em uma alteração macroscópica na superfície de diferentes materiais, ocasionado por microrganismos pertencentes ao grupo dos fungos, que se desenvolvem, normalmente, em unidade acima de 75\% (TORALLES; SOUZA, 2015).

Diante disso, Toralles e Souza (2015) concluíram que as habitações de alvenaria apresentaram percentuais de patologias superiores às de concreto. Ainda, destacaram que a maior parte dos problemas patológicos foram originados da execução da obra, por procedimentos e métodos inapropriados para a ação demandada. Contudo, devido um maior rigor técnico adotado na construção de empreendimentos mais recentes, o número de patologias encontra-se menor. Isso sugere que o melhor caminho para a manifestação de problemas como os descritos está no estabelecimento de um programa de execução bem delimitado.

O foco nas patologias em HIS também foi tema do estudo de Prates, Nascimento e Mendes (2018), quando os autores tiveram o objetivo de identificar as principais e mais 
frequentes manifestações patológicas neste tipo de edificação, diagnosticando suas causas em um conjunto habitacional da cidade de Montes Claros, em Minas Gerais. A pesquisa de campo foi conduzida por meio de fichas de avaliação das casas e observações diretas. No universo de 256 unidades, foram selecionadas is como amostra, de forma aleatória, tendo como critérios estarem finalizadas e ocupadas.

Prates, Nascimento e Mendes (2018) analisaram as ocorrências patológicas em oito grupos, conforme o elemento construtivo, quais sejam: fundações; superestruturas (vergas, contravergas e cintas de armação): esquadrias; alvenaria de elevação (parede): revestimento; piso; cobertura (estrutura e telhamento); pinturas; instalações elétricas e hidráulicas. Foram registradas 282 ocorrências patológicas, sendo que aquelas relacionadas ao revestimento figuraram como o maior percentual $(27,31 \%)$ dentre todas, sendo que os bolores se constituíram enquanto os problemas mais prevalentes. Os revestimentos foram seguidos de cobertura, com $14,54 \%$, e instalações elétricas e hidráulica, com $13,47 \%$. As fundações representam o único elemento construtivo em que não foi observada a presença de patologias.

Os autores destacam que nenhuma manifestação patológica foi considerada grave, e, portanto, não compromete o desempenho estrutural das residências. Além disso, sublinham que problemas encontrados no revestimento, como o bolor, são comuns neste tipo de habitação. Ainda argumentam que a umidade está relacionada à penetração de água pelas paredes, podendo ter origem no projeto, com a definição dos materiais, mas, especialmente, são ocasionados na execução da obra, com aplicação de materiais inadequados ou em função de mão de obra pouco qualificada, dentre outros motivos (PRATES; NASCIMENTO; MENDES, 2018).

$\mathrm{Na}$ pesquisa de Carraro e Dias (2014), os autores tiveram como objetivo contribuir para melhorar a qualidade construtiva de empreendimentos do tipo HIS e diminuir o impacto ambiental causado pela sua degradação prematura, por meio de um estudo de caso exploratório. Secundariamente, houve intenção de identificar as possíveis origens das manifestações patológicas, fazendo relações com a origem de ocorrência, para retroalimentar o processo de projeto, de execução e de utilização das residências. 
A área de estudo foi um conjunto habitacional Jardim das Palmeiras, na cidade de Uberlândia, estado de Minas Gerais. A amostra foi de 13 residências, escolhidas de forma aleatória, desde que habitadas no momento do estudo, dentro de um universo de roo habitações sob a responsabilidade de construção de uma determinada empresa, da qual também foram colhidas informações. Nas visitas técnicas, a coleta de dados foi por meio de entrevistas semiestruturadas com os moradores e registros fotográficos (CARRARO; DIAS, 2014).

No caso da pesquisa de Carraro e Dias (2014), as manifestações patológicas foram categorizadas em quatro grupos, sendo eles: umidade; descolamento de revestimento, fissuras; e irregularidade do acabamento. As manifestações encontradas em cada uma destas categorias foram conflitadas com os documentos que podem estar relacionados com elas, pertencentes às fases de projeto, execução, materiais e uso, este último incluindo manutenção e operação. O gráfico 2, a seguir, mostra os percentuais das patologias na amostra de residências estudadas.

Gráfico 2 - Incidência das manifestações patológicas na amostra estudada

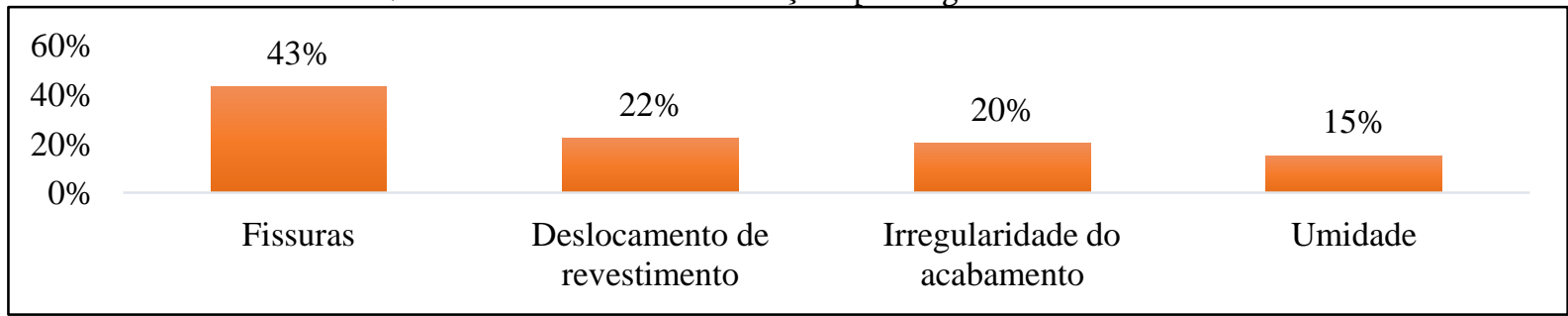

Fonte: Carraro e Dias (2014).

Conforme o Gráfico 3, os tipos de manifestações mais frequentes são as fissuras, com 43\% de representatividade, seguidas de deslocamento de revestimento e irregularidades do acabamento, com percentuais de $22 \%$ e $20 \%$, nesta ordem.

Outro ponto analisado por Carraro e Dias (2014) foi relacionar a presença de patologias com as etapas do processo de construção. Sendo assim, poderiam ser resultantes da fase de execução, projeto ou uso, além dos materiais. O Gráfico 3 evidencia os percentuais dessa relação.

Gráfico 3 - Origem das manifestações patológicas ocorridas nas unidades habitacionais na amostra estudada 


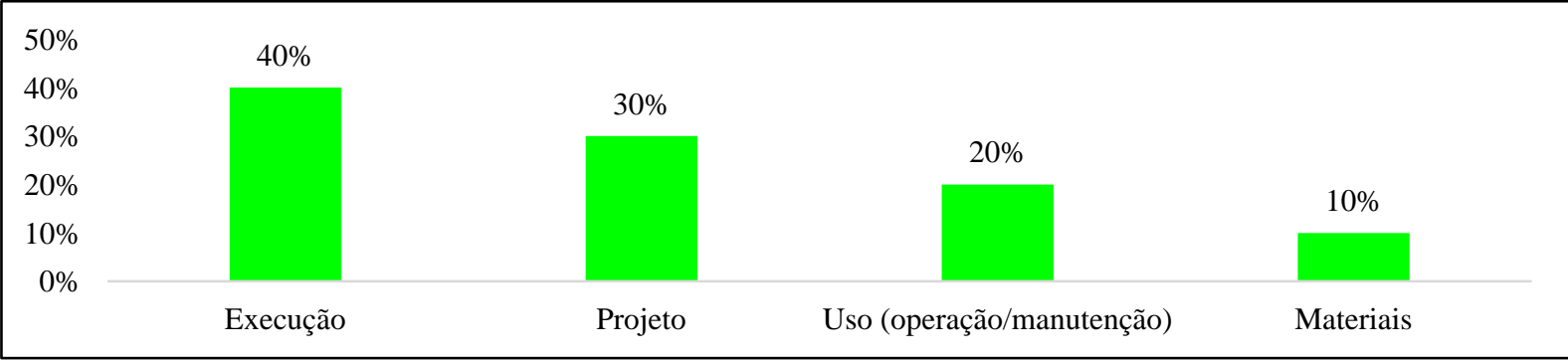

Fonte: Carraro e Dias (2014).

Com base no Gráfico 3, nota-se que a maior parte das patologias é decorrente da fase de execução, totalizando 40\%. Já em relação ao projeto, foi identificado que $30 \%$ das patologias eram resultantes desta etapa, e somente $20 \%$ estavam relacionadas ao uso. Os autores concluíram que o número de patologias é considerado alto, especialmente, considerando que todas as unidades estudadas apresentaram patologias. Além disso, alertam para a necessidade de maior rigor no momento de execução das obras, visto que é a principal fonte de patologias, sendo essencial traçar um plano de medidas preventivas para que as patologias sejam evitadas.

Esta parte do estudo mostrou as principais patologias encontradas em HIS. Assim, independentemente do local em que os estudos aconteceram, haja vista que incluiu diferentes cidades do Brasil, os resultados coadunam para apontarem as fissuras como os problemas patológicos mais frequentes. Além disso, em todos os casos, os autores salientam para a necessidade de maiores cuidados na fase de execução, pois, em conformidade com a literatura, representa a etapa da qual as patologias são originadas.

Importa destacar que a amostra de artigos, em sua maioria, se limitou a identificar as patologias mais prevalentes nas unidades estudadas. Por isso, não foi possível verificar os reparos possíveis em cada um dos casos. Não obstante, isso pode ser em função do tempo de estudo, especialmente, porque, no momento das análises, as habitações não estavam passando por reformas, tampouco os autores informaram que estavam previstas para o futuro.

Outro ponto de alerta diz respeito às medidas corretivas, pois, a maioria dos trabalhos não sugeriu os possíveis manejos das patologias, entretanto, a totalidade dos autores afirma que as melhores medidas para a prevenção dos problemas patológicos 
devem ser tomadas na fase de execução, e, adicionalmente, apontam ser fundamental estabelecer as medidas preventivas na fase de uso.

Apontamento como esses estão de acordo com Cahino (2018), quando seu estudo apontou que as residências apresentam uma ou mais patologia, e que estão atreladas ao projeto, à execução ou à fase de uso/manutenção. Mesmo considerando a presença de problemas como esses, as patologias não comprometeram o desempenho das residências e não ofereceram riscos aos moradores, tal como nos artigos amostrais. Também, assim como os estudos utilizados nesta discussão, a autora argumenta que processos de manutenção periódica tendem a fazer com que as patologias sejam reduzidas ou sequer aconteçam.

\section{CONSIDERAÇÕES FINAIS}

A busca na literatura apontou que esse tema é, relativamente, pouco investigado, considerando certa dificuldade em encontrar artigos. Entretanto, seus achados contribuem para melhores esclarecimentos acerca das manifestações patológicas em edificações como essas.

Em linhas gerais, as produções apontaram que as fissuras figuram como o tipo de patologia mais comum nas HIS. Do ponto de vista quantitativo, essas manifestações são seguidas de deslocamento de revestimento, umidade e bolor (biodeterioração). Resultados como os apresentados evidenciam que os tipos patológicos são basicamente os mesmos, especialmente, quando se verifica que os conjuntos de HIS são de diferentes cidades do Brasil. Além disso, na maioria dos casos, os autores destacaram que as patologias encontradas não apresentavam riscos aos usuários. Contudo, há de se alertar para maiores cuidados referentes à manutenção e ao tratamento das patologias.

Outro foco deste estudo esteve em relacionar as origens das patologias nesse tipo de habitação às etapas de construção. Sendo assim, constatou-se que a gênese principal das manifestações é nas fases de projeto e, especialmente, na etapa de execução da obra. Portanto, figura como a etapa mais crítica, e, por isso, demanda profissionais qualificados para aplicar os procedimentos da forma adequada para cada ação, além de materiais de 
qualidade considerável, a fim de evitar problemas em seu uso regular, durante a utilização da habitação e sua manutenção.

Além desses aspectos, houve pretensão de averiguar as possíveis soluções para os problemas patológicos. Levando-se em conta as manifestações e a relação das patologias com as fases do ciclo de vida das HIS, a literatura mostrou consonância em afirmar que as principais soluções para os problemas apresentados devem partir das fases de projeto e de execução.

Dessa maneira, sustentam que as construtoras responsáveis por esse tipo de empreendimento devem procurar esmiuçar todas as atividades relativas à construção, na tentativa de garantir o desenho de todos os pontos previsíveis, inclusive das possíveis patologias na fase de utilização. Ainda deve incluir uma equipe de profissionais adequadamente qualificados, desde engenheiros até os mestres de obra e demais equipe de pessoal, pois, algumas patologias são decorrentes de má qualidade da mão de obra.

Por se tratar de uma revisão de literatura, esta pesquisa apresenta como limitação o fato de não ter sido levantada nenhuma ação de correção para as patologias encontradas, o que contribuiria para maior aprofundamento do tema, ao evidenciar soluções concretas. Porém, isso é resultado de limitações dos próprios estudos realizados junto às HIS, uma vez que não tiveram como foco intervenções nos locais em que ocorreram, motivo pelo qual não foi aplicado tratamento para as patologias diagnosticadas. Apesar disso, o conhecimento das patologias e das origens dessas manifestações são elementos essenciais para problematizar a necessidade de maior rigor na construção de HIS.

\section{REFERÊNCIAS}

AZEVEDO, S.; ANDRADE, L.A.G. Habitação e Poder: da Fundação da Casa Popular ao Banco Nacional de Habitação. Rio de Janeiro: Centro Edelstein de Pesquisas Sociais, 2oII.

BONDUKI, N. Política habitacional e inclusão social no Brasil: revisão histórica e novas perspectivas no governo Lula. Revista de Arquitetura e Urbanismo, n. I, jan.-dez., 2008. Disponível em: https://revistaarqurb.com.br/arqurb/article/view/8I/75. Acesso em 13 fev. 2021. 
BRASIL. Lei no. Ir.977, de 7 de julho de 2009. Brasília: Casa Civil, 2009. Disponível em: https://www2.camara.leg.br/legin/fed/lei/2009/lei-I1977-7-julho-2009-589206publicacaooriginal-II4I9o-pl.html. Acesso em: I7 maio 202I.

BRASIL. Política Nacional de Habitação. Cadernos Cidades 4. Brasília: Ministério das Cidades, 2004. Disponível em: http://www.capacidades.gov.br/biblioteca/detalhar/id/127/titulo/cadernos-mcidades-4--politica-nacional-de-habitacao. Acesso em: 17 maio 202I.

BRUNA, P. Habitação social no Brasil. Estudos Avançados, v. 29, n. 83, p. 317-326, 2015. Disponível em: https://www.scielo.br/pdf/ea/v29n83/oro3-4014-ea-29-83-00317.pdf. Acesso em: $20 \mathrm{fev}$. 2021.

CAHINO, J. E. M. Avaliação de conjuntos de habitações unifamiliares: análise de manifestações patológicas e vida útil estimada. 2018. 130 f. Dissertação (Mestrado em Engenharia Civil) - Universidade Federal de Pernambuco, Recife, 2or8. Disponível em: http://tede2.unicap.br:8080/bitstream/tede/IIo2/5/jessika_elaine_mendes_cahino.pdf.

Acesso em 13 fev. 2021.

CAMPOS, S.E. Gestão do processo de projetos de edificações em instituição federal de ensino superior: um estudo de caso no CEPLAN/UnB. 2011.226 f. Dissertação (Mestrado em Arquitetura e Urbanismo) - Universidade de Brasília, Brasília, 20Ir. Disponível em: https://repositorio.unb.br/bitstream/I0482/9562/I/20II_SergioEmidioAzevedoCampos.pd f. Acesso em: 20 out. 2020.

CARRARO, C. L.; DIAS, J. F. Diretrizes para prevenção de manifestações patológicas em Habitações de Interesse Social. Ambiente Construído, v. I4, n. 2, p. 125-139, abr./jun., 2014. Disponível em: https://seer.ufrgs.br/ambienteconstruido/article/view/44103/29879. Acesso em 13 fev. 2021.

CARVALHO, A.A.V.; MEDEIROS, V.A.S. O papel do programa Minha casa, minha vida no processo de construção das cidades: a perspectiva configuracional. Revista Brasileira de Gestão Urbana, 9, supl. I, p. 396-407, 2017. Disponível em: https://www.scielo.br/pdf/urbe/v9si/2175-3369-urbe-9-si-396.pdf. Acesso em: I8 mar. 2021.

CUNHA, T.A.; SILVA, M.S. Evidências de imprecisão nas políticas habitacionais brasileiras: o caso de São Paulo. Revista Brasileira de Gestão Urbana, v. ıo, n. I, jan./abr., p. 52-71, 2018. Disponível em: https://www.scielo.br/pdf/urbe/vionI/2175-3369-urbe-Io-I52.pdf. Acesso em: 20 fev. 2021.

GIL, A.C. Como elaborar projetos de pesquisa. 5. ed. São Paulo: Atlas, 2010.

JONOV, C.M.P. et al. Avaliação de danos às edificações causados por inundações e obtenção dos custos de recuperação. Ambiente Construído., Porto Alegre v.I3, n.I, 
jan./mar. 2013. Disponível em: https://www.scielo.br/pdf/ac/vi3ni/vizniao6.pdf. Acesso em: 07 mar. 2021.

MAZER, W. Patologia, recuperação e reforço de estruturas de concreto. Universidade Tecnológica Federal do Paraná, 2008. Disponível em: https://www.docsity.com/pt/patologia-recuperacao-e-reforco-de-estruturas-de-concretoI-I/5005958/. Acesso em: I5 mar. 202I.

MONTEIRO, A.R.; VERAS, A.T.R. A questão habitacional no Brasil. Mercator, Fortaleza, v. I6, p. I- $\quad$ I3, 2017. Disponível em: https://www.scielo.br/pdf/mercator/vi6/1984-220I-mercator-I6-er6or5.pdf. Acesso em: I8 abr. 2021.

PEREIRA, P.S. Programa de manutenção de edifícios para as unidades de atenção primária à saúde da cidade de Juiz de Fora. 20II. Iog f. Dissertação (Mestrado em Ambiente Construído) - Universidade Federal de Juiz de Fora, Juiz de Fora, 2orr. Disponível em: https://www2.ufjf.br/ambienteconstruido//files/2009/o9/Disserta\%c3\%a7\%c3\%a30Priscila-Souza-Pereirar.pdf. Acesso em: i8 fev. 2021.

PERINI, J.I. Estudo de manifestações patológicas em Habitações de Interesse Social construídas em alvenarias de blocos cerâmicos: estudo de caso Bairro Shopping Park em Uberlândia-MG. 2017. 103 f. Dissertação (Mestrado em Engenharia Civil) - Universidade Federal de Uberlândia, Uberlândia, 2017. Disponível em: https://repositorio.ufu.br/bitstream/123456789/21073/r/EstudoManifestacoesPatologicas.p df. Acesso em: I9 maio 202I.

PRATES, A.E.; NASCIMENTO, J.C.; MENDES, K.E. Principais manifestações patológicas em conjunto habitacional de interesse social - Montes Claros/MG. Intercambio, $\quad \mathrm{v}$. $15, \quad \mathrm{n}$. 2, 2019. Disponível em: http://www.intercambio.unimontes.br/index.php/intercambio/article/view/555/43I. Acesso em: io fev. 2021.

RUFINO, M.B.C. Transformação da periferia e novas formas de desigualdades nas metrópoles brasileiras: um olhar sobre as mudanças na produção habitacional. Cadernos Metrópole, São Paulo, v. 18, n. 35, p. 217-236, abr., 2016. Disponível em: https://www.scielo.br/pdf/cm/vi8n35/2236-9996-cm-18-35-0217.pdf. Acesso em 18 fev. 2021.

SANTOS, A. M. S. P.; DUARTE, S. M. Política habitacional no Brasil: uma nova abordagem para um velho problema. Disponível em: https://www.epublicacoes.uerj.br/index.php/rfduerj/article/view/I375/Ir65. Acesso em i3 fev. 202I.

SILVA, A.P.; JONOV, C.M.P. Patologia das construções. Material didático. Especialização em Construção Civil. Universidade Federal de Minas Gerais, Belo 
Horizonte,

2019.

Disponível

em:

http://www.demc.ufmg.br/adriano/Patologia\%2odas\%20Construcoes.pdf. Acesso em: or maio 202I.

STUCKERT, T. C.; SOBRINHO JÚNIOR, A.S. Patologias em habitações de interesse social. InterScientia, v. 4, n. 2, p. I09-122, 2016. Disponível em: https://periodicos.unipe.br/index.php/interscientia/article/view/522. Acesso em: or maio 2021.

TORAllES, B. M.; SOUZA, S. T. M. Manifestações Patológicas em Habitações de Interesse Social com Diferentes Tipologias. Revista de Ciências Exatas e Tecnologia, v. ıo, n. Io, p. 9-19, 2015. $\quad$ Disponível https://revista.pgsskroton.com/index.php/rcext/article/view/3399. Acesso em: or maio 2021. 